\title{
VARIABILITAT EN LA REALITZACIÓ DEL CONSTRAST EN LES SIBILANTS SORDES DEL CATALÀ I DEL ROMANÉS*
}

\author{
VARIATION IN THE REALIZATION OF CATALAN \\ AND ROMANIAN VOICELESS SIBILANT CONTRAST
}

\author{
Paula Cruselles \\ Universitat de València \\ paula.cruselles@uv.es
}

Resum: El romanés i el valencià presenten un contrast similar entre la sibilant no palatal /s/ i la sibilant palatal $/ \delta /$, però l'articulació de les dues consonants presenta diferències entre les dues llengües. D’una banda, en romanés /s/ es realitza com a dental, més avançada que en valencià; de l'altra, IJ/ presenta en romanés un grau de palatalitat major, amb més endarreriment articulatori que en valencià. El primer objectiu és descriure les característiques acústiques d'aquestes consonants a partir del centre de gravetat i comprovar si aquest moment espectral és un bon indicador per a caracteritzar /s/ i / $/$ / en les llengües estudiades. El segon objectiu és determinar si existeixen diferències entre les dues llengües en la nitidesa del contrast/s/ vs. / $/$ /. Les dades demostren que el centre de gravetat permet descriure les diferències d'articulació entre les consonants del català i del romanés. En relació amb la distància entre les dues consonants, podem establir una gradació en valencià des de la manca de distinció fins a una distinció robusta; el romanés es caracteritza per un contrast ben nítid, semblant o més clar que el de les varietats valencianes amb una distinció robusta.

Paraules clau: fonètica acústica, consonants, fricatives, sibilants, romanés, valencià.

$(*)$ Aquest treball ha estat finançat pel programa VALi+d de la Generalitat Valenciana (ACIF/20I6/340). A més, forma part del projecte d'investigació FFI2016-76245-C3-3-P (www.ub.edu/GEVAD), finançat per l'Agencia Estatal de Investigación (AEI) i pel Fons Europeu de Desenvolupament Regional (FEDER), i del grup de recerca GIUV20I3-I37, de la Universitat de València. Agraïsc els comentaris dels assistents al XVIII Col-loqui Internacional de Llengua i Literatures Catalanes celebrat a Bucarest, d'Alina Mihaela Chezan i de les informants romaneses i valencianes, així com els suggeriments i els comentaris dels dos revisors anònims i de Jesús Jiménez i Fernando Sánchez Miret. 
Paula Cruselles

Variabilitat en la realització del contrast en les sibilants sordes del català i del romanés

Abstract: Romanian and Valencian Catalan show a similar contrast between the non-palatal sibilant $/ s /$ and the palatal sibilant $/ \mathrm{J} /$, although the articulation of both consonants displays differences between these two languages. In Romanian /s/ is pronounced as a dental sibilant, more anterior than in Valencian Catalan, and $/ \delta /$ is articulated more palatal, with a more posterior articulation than in Valencian Catalan. Our first goal is to describe the acoustic characteristics of these consonants and to verify if the first spectral moment, center of gravity, is a good indicator to characterize the articulation of the $/ \mathrm{s} /$ and $/ \mathrm{J} /$ in both languages. The second goal is to determine if there are differences in both languages regarding the contrast $/ \mathrm{s} / \mathrm{vs} . / \mathrm{J} /$. Our data show that the center of gravity allows us to describe the differences of articulation between Catalan and Romanian consonants. With respect to the distance between both sibilant, we can stablish a scale in Valencian Catalan that goes from the neutralization to a sharp distinction. In Romanian, on the other hand, there is a robust contrast, similar or sharper than in the Valencian varieties with a more robust distinction.

Key words: acoustic phonetics, consonants, fricatives, sibilants, Romanian, Valencian.

ers ers ers

\section{INTRODUCCIÓ}

En les llengües del món o en els dialectes d'una mateixa llengua els contrastos entre diferents fonemes equivalents o aproximadament equivalents no es realitzen necessàriament amb la mateixa distància entre els sons. En el cas de les fricatives, la possibilitat de variació és especialment gran perquè, en aquests sons, lleugers canvis en la posició dels articuladors poden implicar diferències rellevants en la seua producció final (Ladefoged \& Maddieson 1996). Un bon exemple d'això el trobem en català, en què el parell de fonemes $/ \mathrm{s} / \mathrm{i} / \mathrm{J} /$ presenten en mallorquí i en valencià petits matisos en la seua realització que es tradueixen en diferències notòries en la distància acústica que separa ambdues consonants (v. Recasens \& Espinosa 2006: 136, 2007: 168; Recasens 20I4: 262). Aquesta variació també s'ha observat dintre d'una mateixa varietat de la llengua: en valencià, per exemple, s'ha detectat (Cruselles 2020) una gradació en la realització de l'oposició entre /s/ i / / que va des de la manca de distinció acústica fins a la distinció pronunciada, passant per estadis intermedis amb separació mínima de les dues consonants (l'últim, ja descrit en Cruselles et al. 20I7); és a dir, en valencià es troben, com il.lustrarem en aquest treball, tres models: neutralització completa del contrast, distinció acústica mínima i distinció acústica màxima. Aquesta variació en la realització del contrast entre /s/ i / / s'hauria de donar també entre el català de 
València i el romanés, ateses les característiques articulatòries del contrast /s/vs. / $/$ / en català, concretament en la varietat valenciana (Recasens 20I4: 245-248) i en romanés (Mallinson 1990: 395; Chițoran 2002: Io).

La variació en el contrast entre la sibilant no palatal sorda /s/ i la palatal sorda / / / del català de València i del romanés és justament el centre del nostre estudi. El romanés és un bon exemple d'una llengua romànica amb un contrast no qüestionat entre $/ \mathrm{s} / \mathrm{i}$ $/ \mathrm{J} /$, a diferència del contrast, molt debatut, en valencià entre $/ \mathrm{s} / \mathrm{i} / \mathrm{J} /$. En romanés la distància de realització entre aquestes sibilants és notable, atés que l'alveolar és dental i la / $/$ / és palatal. L'anàlisi d'una llengua amb un contrast ben robust ens permetrà veure fins a quin punt la distància mínima típica del valencià és estàndard, o si, per contra, el patró de distància màxima del valencià s’aproxima més al que trobem en altres llengües. D'aquesta manera, a partir de l'estudi comparatiu entre aquestes dues llengües romàniques, podrem situar en perspectiva les diferents variants del valencià.

La nostra anàlisi vol contribuir, així mateix, a omplir el buit d'estudis experimentals comparatius de les consonants entre aquestes dues llengües. L'estudi segueix l'estel d'altres anàlisis comparatives basades en la caracterització experimental de la realització de les consonants sibilants fricatives a partir de trets acústics, concretament, a partir del primer moment espectral, és a dir, del centre de gravetat. Trobem estudis d'aquest tipus referits tant a llengües romàniques (cf., entre altres, en espanyol: Cicres 20II; Univaso, Martínez Soler \& Gurlekian 20I4; en gallec: Labraña 2005, Regueira 20I4; Regueira \& Guizo 2019, o en portugués: Regueira \& Guizo 2019) com a llengües d'altres branques lingüístiques (cf., entre altres, en anglés: Jongman, Wayland \& Wong 2000; en basc: Hualde 20IO; en polonés: Nowak 2006 o en llengües com l'aleutià, l'apatxe occidental, el chickasaw, el gaèlic, el hupa, el salish de Montana i el toda: Gordon, Barthmaier \& Sands 2002).

L'objectiu d'aquest treball és presentar una mostra dels patrons de diferenciació del contrast $/ \mathrm{s} / \mathrm{i} / \mathrm{J} /$ en valencià i comprovar en quin punt de l'escala se situa el romanés respecte d'aquests models. Amb aquest objectiu, expliquem, en primer lloc, els antecedents del contrast /s/ vs. / $/$ en valencià i en romanés (apartat 2). Tot seguit, comentem els mètodes experimentals i estadístics usats en el treball (apartat 3). En l'apartat 4 exposem els objectius i les hipòtesis que pretenem demostrar. A continuació, presentem els resultats de l'estudi, que ens permeten descriure els trets acústics de les sibilants coronals objecte d'estudi, així com les diferències detectades entre les dues llengües (apartat 5). Finalment, el treball es tanca amb les conclusions (apartat 6). 
Paula Cruselles

Variabilitat en la realització del contrast en les sibilants sordes del català i del romanés

\section{ANTECEDENTS: EL CONTRAST /S/ VS. / // EN VALENCIÀ I ROMANÉS}

L'estatus fonològic de / $/$ / no presenta la mateixa situació en aquestes dues llengües. El contrast /s/vs. / $/$ / ha estat qüestionat per alguns lingüistes quan es tracta del valencià. El debat se centra en l'estatus fonemàtic de la consonant alveolopalatal sorda en aquesta varietat. Per a alguns estudiosos, el fet que / $/$ / aparega amb una semivocal /j/ prèvia habitualment, com en caixa ['kaj $\left.\int \mathrm{a}\right]$, permet defensar que la sibilant palatal no és un fonema, sinó una variant contextual de /s/ (cf., entre altres, Nebot 1996; Colón 1970; Casanova 1990; Jiménez 1996; Saborit 2009). A més, s’hi suma la manca generalitzada d'aquest fonema / / / en el valencià septentrional (Colón 1970). És difícil trobar, en efecte, parells mínims com ara, is vs. ix o París vs. parix, en què /s/ i / / / se separen únicament pel punt d'articulació de la consonant, sense el suport de la presència de la semivocal al davant. Altres lingüistes sostenen, per contra, que el tret palatal sí que té qualitat distintiva, especialment en aquells dialectes (orientals sobretot, però també en algunes varietats valencianes) en què / $/$ / apareix sense la semivocal al davant, com en caixa ['kafa] (cf. Rafel I98I; Garcia \& Beltran I994; Beltran 1997). Que hi haja alguns -comptats- parells mínims com els esmentats abans reforçaria aquesta teoria. Darrerament, en estudis experimentals com Recasens \& Espinosa (2006, 2007), Recasens (2014) i Cruselles, Herrero \& Jiménez (2017) s'ha demostrat, efectivament, l'existència d'una separació clara entre /s/ i / / / en valencià, tret de les zones neutralitzadores septentrionals, tot i que amb una distància en la realització de les dues consonants menor que en altres varietats del català com el mallorquí o el català oriental.

En canvi, en romanés, sembla no haver-hi cap dubte que $/ \int /$ funciona com un fonema diferenciat de la sibilant coronal, que es representa com a $/ \mathrm{s} /$ atés el seu caràcter dental (v. Mallinson 1990: 395; Chiţoran 2002: IO). Una prova fefaent d'aquest contrast és l'existència de múltiples parells mínims, especialment en contacte amb una vocal $a$, com ara en casa 'habitatge', amb /s/, vs. caşa 'drap de llana', amb / $/ \mathrm{J} /$ o pasa 'futbol', amb /s / , vs. paşa 'governador de l'Imperi Otomà', amb / $/$. Des del punt de vista descriptiu, el nostre treball completa els estudis de palatalització del romanés de Spinu (2007, 2010); Spinu, Vogel \& Bunnell (20I2) i Spinu \& Lilley (2016), en ampliar la informació sobre l'articulació de la palatal sorda / $/$ / i relacionar-la amb la producció d'aquesta consonant en català. 


\section{METODOLOGIA}

Per a l'estudi comparatiu de la pronúncia de les sibilants en romanés i en valencià s'han recollit mostres d'informants de les dues llengües. Per una banda, s'han gravat 5 dones romaneses, de pares de procedència romanesa, de $20 \mathrm{a} 24$ anys i originàries de la zona de Bucarest (identificades al llarg del treball com a Ro-AC, Ro-AD, Ro-AM, Ro-BU, Ro-CT). Totes tenen com a llengua materna el romanés, pertanyen al dialecte dacoromanés, tenen coneixements d'espanyol $i$, tot i que en menor grau, també de català. S'han seleccionat totes les informants de la mateixa àrea perquè només volem un punt de referència per als objectius del nostre estudi: la comparació del contrast /s/ vs. / $/$ / en valencià i en romanés; no tenim, doncs, l'objectiu de tractar en aquesta anàlisi tota la variació dialectal que puga haver-hi en romanés. Pel que fa a les dades del valencià, s'han enregistrat 44 dones d'entre 20 i 26 anys i s'han triat 3 subjectes que representen els models generals de realització del contrast analitzat: sense distinció acústica, amb distinció acústica mínima i amb distinció acústica màxima (Cruselles 2020). Les informants provenen d'Albocàsser (Va-MC), que s'inscriu en valencià tortosí; de Riba-roja (Va-MB), pertanyent al valencià central, i, de Crevillent (Va-SM), que forma part del valencià alacantí. En el cas de les informants valencianes, totes tenen pares valencianoparlants que provenen de la mateixa comarca en què se situa la localitat de les informants. En els dos casos s'ha seleccionat dones perquè el corpus fora més homogeni, amb informants de característiques fisiològiques semblants. Totes les gravacions s'han realitzat en entorns silenciosos amb un micròfon cardioide i de condensador (AKG C520L) i una gravadora digital $\left(\mathrm{Zoom} \mathrm{H}_{4}\right)$, amb una freqüència de mostreig de $48 \mathrm{kHz}$ i una qualitat de 32 bits. Les informants han accedit de forma voluntària a realitzar les gravacions i no han rebut cap compensació econòmica.

L'anàlisi acústica de les consonants sibilants sordes s'ha dut a terme amb el programa Praat (Boersma \& Weenink, 20I4). La segmentació de les consonants i l'etiquetatge s'ha realitzat de manera manual a partir de la informació que proporciona l'oscil-lograma i l'espectrograma. Pel que fa al paràmetre escollit, hem seleccionat el primer moment espectral: el centre de gravetat (d'ara endavant, CDG), que assenyala la freqüència mitjana de concentració de l'energia en l'espectre d'un so. El CDG es relaciona amb el punt d'articulació de les sibilants sordes: un valor de CDG baix indica una realització més posterior, més palatal, mentre que un valor més elevat apunta a una producció més anterior (Jongman, Wayland \& Wong 2000). Per a extraure el CDG de cadascuna de les sibilants analitzades, s'ha emprat un script de Praat; aquest script extrau el primer moment espectral a partir d'un període de $20 \mathrm{~ms}$ situat en el centre de la fricció de la consonant, fet que permet evitar la contaminació

Caplletra 71 (Tardor, 2021), p. 95-120 
de les transicions cap als sons contigus. Prèviament, el senyal s'ha filtrat per damunt dels II.00o Hz, atés que aquesta regió ja no es considera rellevant per a l'estudi de les sibilants fricatives sordes, i també per sota dels I.00o Hz per a evitar possibles traces de sonorització parcial.

Hem utilitzat dos corpus per a obtenir les dades acústiques de les sibilants fricatives sordes analitzades. En romanés, s'han seleccionat dues paraules en què apareix la consonant fricativa sorda objecte d'estudi en una síl-laba tònica i en context intervocàlic, envoltada de dues vocals $a$ : una que inclou l'alveolar sorda dental /s/: vasal, i una altra que conté la palatal sorda $/ \delta /:$ aşa; aquestes dues paraules s'han introduït en la frase marc Îţi zic __ 'Et dic___ (I). En valencià, també s'ha seguit el mateix patró; s'han triat dues paraules que contenen els elements analitzats en posició intervocàlica, entre dues /a/, davant d'una vocal tònica (2).

(I) Oracions marc per a extraure dades acústiques del contrast entre l'alveolar dental /s/ i la palatal / $/$ / en romanés
a. Îţi zic vasal
'Et diré vassall
b. Îți zic aşa
'Et diré aixi'

(2) Oracions marc per a extraure dades acústiques del contrast entre l'alveolar /s/ i l'alveolopalatal / $\mathrm{S} /$ en valencià
a. De l'any passat
b. M'ho va baixar

Les oracions emprades al corpus valencià de l'estudi es basen en part en les oracions utilitzades en Recasens \& Espinosa (2006), en el qual es realitza una anàlisi del contrast entre les sibilants en valencià i en mallorquí. La tria del context vocàlic, és a dir, la ubicació de les sibilants entre vocals baixes, respon a raons de productivitat del contrast /s/ vs. / $/$ / en romanés, atés que existeix una quantitat molt reduïda de mots amb consonant palatal sorda en contextos intervocàlics simètrics amb $i$ i $u$. En valencià, també s'han preferit estudiar les consonants en context intervocàlic amb $a$, en primer lloc, per a obtenir un corpus completament comparable amb el del romanés, en què, com acabem de dir, no es facil trobar exemples amb altres vocals. En segon lloc, la consonant alveolopalatal es volia estudiar en un context que no incloguera la vocal /i/, per a comprovar el grau de palatalitat sense la influència d'una vocal palatal. Finalment, també s'ha evitat el tercer context possible, en què les sibilants estan envoltades per la vocal /u/, perquè els mots amb / $/$ / que ens podrien servir d'exemple, com gruixut, no són habituals en la parla col-loquial del valencià. Per això, els parlants, fins i tot els que no presenten $/ \mathrm{J} /$ en la seua varietat, podrien reproduir-lo tal com l'han 
aprés a l'escola, amb el so alveolopalatal [S] per a la grafia $<$ ix $>$. D'aquesta manera, si usem parells comuns en la parla col-loquial com passat i baixar ens assegurem major probabilitat que els produïsquen com en el seu dialecte habitualment. D'altra banda, en cap de les dues llengües no s'han triat paraules en què les dues vocals contigües diferiren, com ara embussar $\sim$ dibuixar, per a evitar l'efecte creuat de la coarticulació amb aquestes vocals, és a dir, que la consonant es poguera veure influïda per una de les vocals en una direcció en alguns casos i per l'altra vocal en una direcció distinta en uns altres.

Les oracions han estat repetides per les informants io vegades, de les quals s'han analitzat 7 repeticions. D'entrada, s'han descartat la primera i l'última repetició per a evitar problemes en l'articulació; concretament, s'elimina la primera repetició per a defugir possibles equivocacions per desconeixement de la paraula i l'última per a eludir la davallada tonal típica dels elements finals d'una enumeració. També s'ha descartat regularment l'antepenúltima repetició en totes les informants, que s'ha gravat com a comodí per si en la fase de segmentació i etiquetatge es descobria una anomalia en alguna de les 7 repeticions restants.

A partir dels valors de CDG, i amb la finalitat de conéixer les diferències de realització globals entre les informants romaneses i valencianes respecte de les sibilants coronals sordes estudiades, s'han realitzat dues proves $\mathrm{ANOVA}^{1} \mathrm{~d}^{\prime}$ un factor amb el programa SPSS versió 24 (IBM Corp., 20I6). Com es pot comprovar en la Taula I, en la primera prova s'ha utilitzat com a variable dependent el valor del CDG de les realitzacions de /s/ en valencià i de/s/ en romanés (v. les dades concretes a l'Annex I). En la segona prova s'ha emprat com a variable dependent el valor per al CDG de la realització de $/ \delta /$ en valencià i en romanés. Per a determinar si existeixen diferències en la distància entre el CDG dels dos parells de sons entre les informants romaneses i valencianes, i també entre les informants de la mateixa llengua, s'ha dut a terme una tercera prova ANOVA d'un factor en què s'ha definit com a variable dependent el valor de la diferència del CDG entre $/ \mathrm{s} / \sim / \mathrm{s} / \mathrm{vs}$. $/ \mathrm{J} /$. Per a definir aquesta última variable, els valors de la diferència de CDG, hem emparellat de manera aleatòria els valors de CDG dels estímuls de les dues consonants segons l'ordre en què van ser

1. Com és habitual en les ciències experimentals, el nivell de significació de les proves se situa en $p=$ 0,05 . En tots els tests, quan hi ha diferències significatives de la variable dependent en relació amb els diferents parlants, ço és, quan els tests indiquen que tots els parlants no formen part d'un únic grup, s'ha aplicat la prova post-hoc de Scheffé per a determinar les agrupacions dels subjectes, atés que, en tots els casos, les variàncies dels diferents grups són equivalents segons la prova de Levene. Les proves post-hoc permeten conéixer com s'agrupen els subjectes i el valor de probabilitat de les agrupacions, en una escala de o a i: com menor siga el valor, menor serà el grau de cohesió del grup i, com major siga el valor, major serà la consistència del grup.

Caplletra 71 (Tardor, 2021), p. 95-120 
Paula Cruselles

Variabilitat en la realització del contrast en les sibilants sordes del català i del romanés

pronunciades per cada subjecte; és a dir, hem restat al valor del CDG de la primera /s/ del parlant romanés Ro-AC el CDG de la primera / / / d'aquest mateix parlant, i així successivament (v. Annex I). En tots els casos, s'han utilitzat els diferents subjectes de l'estudi com a variable independent; volem, doncs, escatir si els parlants es poden classificar en diferents grups respecte de les variables dependents estudiades.

Taula I. Variables definides per a l'anàlisi estadística dels contrastos de les sibilants fricatives sordes en romanés i en valencià

\begin{tabular}{|c|c|}
\hline $\begin{array}{c}\text { Variable } \\
\text { independent }\end{array}$ & $\begin{array}{c}\text { Variable } \\
\text { dependent }\end{array}$ \\
\hline Subjecte & $\begin{array}{l}\text { Prova 1. Valors de centre de gravetat }(\mathrm{CDG}) \text { de sibilant dental / alveolar } \\
(/ \mathrm{s} / \sim / \mathrm{s} /) \\
\text { Prova 2. Valors de centre de gravetat }(\mathrm{CDG}) \text { de la sibilant alveolopalatal / } \\
\text { palatal }(/ \mathrm{J} /) \\
\text { Prova 3. Diferència del valor de centre de gravetat }(\mathrm{CDG}) \text { entre la sibilant } \\
\text { dental / alveolar }(/ \mathrm{s} / / / \mathrm{s} /) \text { i la palatal }(/ \mathrm{J} /)\end{array}$ \\
\hline
\end{tabular}

\section{OBJECTIUS I HIPÒTESIS}

Com hem dit abans, l'objectiu principal d'aquest estudi és analitzar les diferències existents entre el romanés i el valencià en la producció del contrast dels fonemes fricatius sords / $/$ / i / / quan apareixen entre dues vocals baixes. Aquesta anàlisi comparativa de les sibilants sordes en romanés i en valencià presenta cinc objectius més específics. La primera finalitat de l'estudi és descriure, a partir del valor de CDG, la realització de /s/ tant en les informants romaneses com en les valencianes, per a constatar les similituds i les diferències d'aquesta sibilant en aquestes dues llengües romàniques. D'acord amb la bibliografia, en romanés s'espera una producció de la sibilant més anterior, atés que el seu punt d'articulació és dental, representat habitualment com a/s/s/ (Mallinson I990: 395; Chițoran 2002: I0), mentre que en valencià aquesta sibilant sorda es caracteritza com a alveolar $\mathrm{i}$, per tant, s'hauria de realitzar en un punt articulatori més posterior (Sanchis Guarner 1950: 83; Saborit 2009: 65; Recasens \& Espinosa 2006, 2007). D'acord amb aquestes previsions, esperem tenir un valor de CDG clarament més alt en romanés. El segon objectiu és comprovar, a partir del mateix paràmetre acústic, les diferències en la producció de / $/$ / en romanés i en valencià. Segons la bibliografia, la realització d'aquesta sibilant sorda és alveolopalatal en valencià (Prieto 2004: 200) 
i palatal en romanés (Chițoran 2002: 10), fet que es tradueix en una articulació més anterior en valencià i més posterior en romanés, és a dir, amb un valor de CDG més baix en romanés. El tercer objectiu és comprovar, també a partir del CDG, quina distància acústica existeix en romanés entre la sibilant coronal sorda (realitzada com a dental) i la sibilant palatal sorda $/ / /$ i establir en quin punt se situa aquest valor en l'escala de tres posicions corresponent a l'oposició entre les sibilants sordes del valencià (Cruselles 2020). Si es consideren els punts d'articulació del romanés i del valencià descrits en la bibliografia, s'espera una major diferència articulatòria entre les sibilants sordes del romanés, perquè la distància entre el punt d'articulació dental de $/ \mathrm{s} /$ i el palatal de / $/$ / en romanés és major que la distància entre la producció alveolar de /s/ i alveolopalatal de / / / en català. Així mateix, es pretén determinar si el comportament en relació amb la realització del contrast entre les sibilants és homogeni entre les informants romaneses o si, per contra, hi ha subagrupacions dels subjectes en diferents graus de distinció, seguint el comportament del valencià (v. també Cruselles 2020). L'últim aspecte que volem analitzar és la variabilitat interna de les consonants en cada llengua; en principi, la major separació en romanés entre els punts d'articulació de les consonants permetria una major dispersió en la realització de les sibilants, reflectida en la desviació estàndard dels valors, sense possibilitats de confusió. Amb tot, l'escassa variació dialectal del romanés (v. Lamuela 2006: I-2) i el perfil homogeni de les informants pot influir en un grau baix de variació en aquesta llengua. En valencià, en canvi, la possibilitat de confusió entre les dues sibilants hauria de traduir-se en una menor variació interna de les realitzacions.

\section{RESULTATS}

5.I DESCRIPCIÓ ACÚSTICA DE LA SIBILANT DENTAL/ALVEOLAR EN ROMANÉS I EN VALENCIÀ

En aquest apartat exposem els resultats del test ANOVA d'un factor usat per a determinar els trets acústics que caracteritzen la sibilant sorda /s/ en valencià i $/ \mathbf{s} /$ en romanés, que ens permetran deduir quines diferències de realització es donen entre aquestes llengües. L'anàlisi del CDG revela que hi ha diferències en la realització de la sibilant sorda coronal en el conjunt de les informants $\left[\mathrm{F}_{(7,48)}=8 \mathrm{I}, 32 \mathrm{I}, p<0, \mathrm{OOI}\right]$. D'acord amb la prova post-hoc de Scheffé, els resultats de la qual es mostren a la Taula 2, s'adverteix, en primer lloc, una separació nítida per llengües: les mitjanes de CDG de les /s/ produïdes per les informants romaneses no coincideixen amb 
cap de les subagrupacions dels valors mitjans de CDG de les sibilants realitzades per les informants valencianes entrevistades. Els resultats, d'acord amb les expectatives, mostren unes mitjanes més elevades en les consonants coronals romaneses, entre els $7.800 \mathrm{~Hz}$ i els $9.200 \mathrm{~Hz}$, valors que indiquen que el punt d'articulació es realitza més avançat, com correspon al tret dental característic de la / $/$ romanesa. En canvi, les participants valencianes analitzades presenten uns valors de realització de /s/ inferiors, entre $5.300 \mathrm{~Hz}$ i $6.900 \mathrm{~Hz}$, aquestes xifres corresponen a un punt d'articulació més posterior que la $/ \mathbf{s} /$ romanesa, fet que corrobora el caràcter alveolar de la /s/ valenciana. Convé subratllar, d'altra banda, que, en conjunt, els rangs dels valors de les mitjanes de les informants valencianes i de les romaneses són aproximadament equivalents, al voltant de $\mathrm{I} .500 \mathrm{~Hz}$, és a dir, considerant els subjectes seleccionats, la variació en la realització de la sibilant alveolar és semblant en ambdues llengües.

Taula 2. Agrupacions de les mitjanes del valor de centre de gravetat (CDG, en $\mathrm{Hz}$ ) de la sibilant sorda alveolar /s/ (entre parèntesis, desviació estàndard del centre de gravetat). Per a major claredat, ombregem les caselles corresponents a les informants valencianes.

\begin{tabular}{|c|c|c|c|c|c|c|}
\hline \multirow[b]{2}{*}{ Subjecte } & \multirow[b]{2}{*}{ Casos } & \multicolumn{5}{|c|}{ Agrupacions } \\
\hline & & 1 & 2 & 3 & 4 & 5 \\
\hline Va-MC & 7 & $\begin{array}{l}5.374 \\
(538)\end{array}$ & & & & \\
\hline Va-MB & 7 & & $\begin{array}{l}6.439 \\
(360)\end{array}$ & & & \\
\hline Va-SM & 7 & & $\begin{array}{l}6.909 \\
(275) \\
\end{array}$ & & & \\
\hline Ro-BU & 7 & & & $\begin{array}{l}7.858 \\
(189)\end{array}$ & & \\
\hline Ro-AC & 7 & & & $\begin{array}{l}8.125 \\
(245)\end{array}$ & $\begin{array}{l}8.125 \\
(245)\end{array}$ & \\
\hline Ro-CT & 7 & & & & $\begin{array}{l}8.934 \\
(445)\end{array}$ & $\begin{array}{l}8.934 \\
(445) \\
\end{array}$ \\
\hline Ro-AD & 7 & & & & & $\begin{array}{l}9.247 \\
(281) \\
\end{array}$ \\
\hline Ro-AM & 7 & & & & & $\begin{array}{l}9.274 \\
(727) \\
\end{array}$ \\
\hline \multicolumn{2}{|c|}{ Sign. } & 1 & 0,727 & 0,983 & 0,095 & 0,936 \\
\hline
\end{tabular}


A més, hi ha bastant variació interna en les dues llengües, com demostra el fet que els subjectes no tendeixen a formar un únic grup en cap de les llengües. L'anàlisi intragrups de les /s/ mostra, en el cas valencià, que el subjecte Va-MC, d'Albocàsser, realitza aquesta sibilant sorda de manera diferenciada de les altres informants valencianes (Va-MB, de Riba-roja, i Va-SM, de Crevillent). Concretament, Va-MC presenta uns valors de mitjana de CDG més baixos $(5.374 \mathrm{~Hz}) \mathrm{i}$, per tant, realitza la consonant amb un grau major de posterioritat que Va-MB i Va-SM. Les darreres informants produeixen /s/ de manera similar, amb uns valors més elevats, entre $6.400 \mathrm{~Hz}$ i 6.900 $\mathrm{Hz}$, cosa que indica una articulació més avançada de la consonant alveolar. A més, el valor de la desviació estàndard de Va-MC és superior al de les altres informants valencianes, fet que indica major variació en la seua producció. En conjunt, doncs, s'adverteixen dues tendències en la realització d'aquesta sibilant en valencià: el subjecte Va-MC, d'Albocàsser, presenta una realització més posterior i amb més variació de /s/, mentre que Va-MB, de Riba-roja, i Va-SM, de Crevillent, produeixen aquesta consonant més anterior i amb menor variació.

Si ens fixem en el grup de les informants romaneses, també observem que existeixen diferències internes respecte de la realització de /s/. Advertim, en primer lloc, dues realitzacions molt distanciades: Ro-BU, amb un valor mitjà de CDG per davall de $8.000 \mathrm{~Hz}$, és el subjecte que produeix /s/ amb major posterioritat (tot i no ser diferent estadísticament de Ro-AC); per contra, Ro-AD i Ro-AM, amb un valor mitjà de CDG que supera els $9.000 \mathrm{~Hz}$, presenten la realització més avançada de /s/ d'entre els subjectes analitzats (tot i que tampoc no és diferent de Ro-CT). Aquestes tres informants són les úniques que pertanyen a una única agrupació. D’altra banda, els subjectes intermedis, Ro-AC i Ro-CT, tot i poder conformar un grup independent de baixa probabilitat $(p=0,095)$, presenten valors que es poden agrupar per separat amb els subjectes dels grups extrems amb valors de probabilitat alts en el test de Scheffé: d'aquesta manera, la realització de /s/ de Ro-AC, amb un valor al voltant de 8.000 $\mathrm{Hz}$, s'agruparia preferentment amb Ro-BU ( $p=0,983)$; per contra, Ro-CT, amb una freqüència de realització de /s/ al voltant de $9.000 \mathrm{~Hz}$, formaria un grup més probable amb els subjectes Ro-AD i Ro-AM $(p=0,936)$. Finalment, s'observa que la variabilitat de les realitzacions tendeix a augmentar quan el valor del CDG és més elevat, malgrat que no podem afirmar que siga una pauta clara perquè la informant Ro-AD es desmarca d'aquesta tendència. Per tant, podem concloure que el grup de parlants romaneses presenta, a grans trets, dos grups principals respecte de la pronúncia de la consonant dental /s/, semblantment al que ocorre en valencià. 


\subsection{DESCRIPCIÓ ACÚSTICA DE LA SIBILANT SORDA / / EN ROMANÉS I EN VALENCIÀ}

Tot seguit, exposem els resultats del test ANOVA d'un factor usat per a analitzar els trets acústics que caracteritzen la sibilant sorda $/ \int /$ en les llengües estudiades. La descripció tradicional de la producció de la consonant sibilant sorda / $/$ fa preveure, com hem dit abans, que en valencià es realitza com a alveolopalatal i que en romanés s'articula en una posició més posterior, com a palatal. Per tant, esperem una diferència entre les dues llengües, amb valors de CDG més baixos en romanés. Tanmateix, els resultats no mostren una divisió clara entre l'articulació de les dues llengües: l'anàlisi del test ANOVA, en efecte, mostra diferències en les realitzacions de / $\mathrm{f} /$ per part dels subjectes $\left[\mathrm{F}_{(7,48)}=38,9 \mathrm{I} 8, p<\mathrm{O}, \mathrm{OO} \mathrm{I}\right]$, però, com es pot comprovar en la Taula 3 , no s'observen dos grups diferenciats segons la llengua, contràriament al que esperàvem i a diferència del que ocorria amb la sibilant alveolar.

Taula 3. Agrupacions de les mitjanes del valor de centre de gravetat (CDG, en $\mathrm{Hz}$ ) de la sibilant / / / (entre parèntesis, desviació estàndard del CDG). Per a major claredat, ombregem les caselles corresponents a les informants valencianes.

\begin{tabular}{|c|c|c|c|c|c|}
\hline \multirow[b]{2}{*}{ Subjecte } & \multirow[b]{2}{*}{ Casos } & \multicolumn{4}{|c|}{ Agrupacions } \\
\hline & & 1 & 2 & 3 & 4 \\
\hline Ro-BU & 7 & $\begin{array}{l}3.953 \\
(302) \\
\end{array}$ & & & \\
\hline Va-SM & 7 & $\begin{array}{l}4.346 \\
(242)\end{array}$ & $\begin{array}{l}4.346 \\
(242)\end{array}$ & & \\
\hline Ro-AD & 7 & $\begin{array}{l}4.472 \\
(377) \\
\end{array}$ & $\begin{array}{l}4.472 \\
(377) \\
\end{array}$ & & \\
\hline Ro-AC & 7 & $\begin{array}{l}4.531 \\
(230)\end{array}$ & $\begin{array}{l}4.531 \\
(230)\end{array}$ & & \\
\hline Ro-AM & 7 & $\begin{array}{l}4.826 \\
(739) \\
\end{array}$ & $\begin{array}{l}4.826 \\
(739) \\
\end{array}$ & $\begin{array}{l}4.826 \\
(739) \\
\end{array}$ & \\
\hline Ro-CT & 7 & & $\begin{array}{l}4.898 \\
(459) \\
\end{array}$ & $\begin{array}{l}4.898 \\
(459)\end{array}$ & \\
\hline Va-MB & 7 & & & $\begin{array}{l}5.557 \\
(276) \\
\end{array}$ & \\
\hline Va-MC & 7 & & & & $\begin{array}{r}7.095 \\
(458) \\
\end{array}$ \\
\hline Sign. & & 0,051 & 0,530 & 0,176 & 1 \\
\hline
\end{tabular}


L'anàlisi intergrups de parlants de les dues llengües mostra, en primer lloc, que en valencià $\mathrm{Va}-\mathrm{MC}$ realitza el so corresponent a la grafia $<\mathrm{x}>$ en el mot baixar com una sibilant avançada, és a dir, la realitza en freqüències superiors als $7.000 \mathrm{~Hz}$, en un punt fins i tot superior al de la consonant $/ s /(5.374 \mathrm{~Hz})$. Aquest resultat és esperable en part, atés que la informant procedeix d'Albocàsser, una localitat pertanyent a la varietat més septentrional del valencià, on, d'acord amb la bibliografia, el fonema IS/ s'ha neutralitzat amb l'alveolar sorda /s/ (Colón 1970; Saborit 2009: 69; Beltran \& Segura-Llopes 2017: I00); tanmateix, la inversió dels valors entre $/ \mathrm{g} / \mathrm{i} / \mathrm{s} /$ no és esperable, ja que haurien de ser semblants (sobre aquesta qüestió, v. la discussió a $\$$ 5.3). Entre els subjectes, s'observa que Va-MB presenta una realització de / $/ \mathrm{amb}$ un valor superior a $5.000 \mathrm{~Hz}$ i que pot agrupar-se amb dues parlants romaneses, Ro-CT i Ro-AM, tot i que amb un valor de probabilitat baix $(p=0,176)$. Finalment, hi ha una tercera participant, Va-SM, que realitza la sibilant $/ \mathrm{J} / \mathrm{amb}$ un valor inferior al de les participants romaneses Ro-AD, Ro-AC i Ro-AM, i només superior al de la informant Ro-BU; amb tot, es pot agrupar amb totes aquestes informants, és a dir, queda clar que aquesta informant valenciana no realitza $/ \mathrm{J} /$ de manera diferent de les participants romaneses. Tenim, per tant, tres grups en valencià pel que fa a la realització de $/ \delta /$.

Quant a l'estudi de les realitzacions de / $/$ / dintre del romanés, com es veu en la Taula 3, tret de la informant Ro-BU, classificada per la prova post-hoc de Scheffé en un sol grup amb una realització inferior a $4.000 \mathrm{~Hz}$, la resta de subjectes romaneses, tendeixen a realitzar la sibilant fricativa palatal amb una freqüència entre $4.472 \mathrm{~Hz}$ i $4.898 \mathrm{~Hz}$. La significació dels grups ens indica un major grau d'afinitat en el grup 2 $[p=0,530]$, en què s'inclouen totes les informants romaneses excepte Ro-BU, que no en el grup I $[p=0,05 \mathrm{I}]$, en el qual s'inclou Ro-BU, però no Ro-CT. S'adverteix, doncs, entre els subjectes analitzats una majoria amb una articulació homogènia i una informant, Ro-BU, amb un comportament que s'allunya d'aquesta tendència. En conjunt, el comportament respecte de la realització de la consonant alveolopalatal sorda /S/ en romanés -bastant homogeni- és diferent del que es dona entre les participants valencianes $-\mathrm{amb}$ tres grups clarament definits.

Finalment, a diferència de la similitud del rang de variació entre la producció de /s/ en romanés i en valencià, amb la sibilant sorda / $/$ / el rang és molt diferent. En valencià el rang de realització d'aquesta consonant se situa en I.2II Hz entre les informants valencianes, si excloem la participant no distingidora d'Albocàsser, un valor que s'acosta al rang de $1.500 \mathrm{~Hz}$ en la realització de /s/ de les informants. Contràriament, entre les participants romaneses la variació disminueix en la producció de la consonant sibilant sorda palatal, atés que trobem una variació de només $945 \mathrm{~Hz}$, inferior 
Paula Cruselles

Variabilitat en la realització del contrast en les sibilants sordes del català i del romanés

als $1.500 \mathrm{~Hz}$ que presenten en la producció de /s/. Aquest menor grau de variació en la realització de / $/$ / en romanés indica una articulació endarrerida més compacta entre les informants romaneses, cosa que s'ajusta a la tendència a agrupar-se en un sol conjunt. D'altra banda, igual com s'ha detectat en l'estudi de la /s/, la variabilitat de / / / només segueix un patró clar en les informants valencianes: així, en la realització de la I $/$, el valor més elevat de desviació típica s'observa en el subjecte Va-MC, mentre que les informants Va-SM i Va-MB, que realitzen / / / amb major posterioritat, presenten menor variabilitat. Per contra, en les informants romaneses, no s'adverteix tampoc cap pauta en els diferents valors de desviació típica, és a dir, no es verifica la hipòtesi que a major distància entre $/ \mathrm{g} / \mathrm{i} / \mathrm{s} /$ es permet més variabilitat interna.

$5 \cdot 3$ ANÀLISI COMPARATIVA DE LA DISTINCIÓ DE / $/$ / / S/ VS. / / EN ROMANÉS I EN VALENCIÀ

En aquest apartat, analitzem la diferència entre les dues consonants sibilants, prenent com a base la diferència dels valors del CDG del contrast/s/vs. / $/$ / en romanés $\mathrm{i} / \mathrm{s} / \mathrm{vs}$. / $/$ / en valencià. Per començar, l'estudi revela que hi ha diferències en aquest contrast entre les llengües analitzades $\left[\mathrm{F}_{(7,4)}=97,33 \mathrm{I}, p<0,00 \mathrm{I}\right]$. L'anàlisi de la diferència mitjana del CDG indica, com mostra la Taula 4 , una realització diferenciada entre les informants valencianes, fet que corrobora la distribució de les informants en tres grups distints (Cruselles 2020). En primer lloc, s'observa que la informant Va-MC presenta una diferència negativa, de $-\mathrm{I} .720 \mathrm{~Hz}$, de mitjana de CDG entre /s/ $\mathrm{i} / \mathrm{J} /$, la qual cosa indica que realitza $/ \mathrm{s} / \mathrm{amb}$ una articulació més posterior, més palatal, mentre que produeix / $/$ / més anterior, és a dir, més alveolar. Aquesta informant està confonent totalment els segments sibilants sords analitzats, atés que és inimaginable que haja invertit els valors per a mantenir la diferència. En l'extrem oposat observem la informant Va-SM, que, amb una diferència de $2.563 \mathrm{~Hz}$ entre /s/ vs. / $/$ /, és la participant valenciana que major distanciament presenta en la realització de les dues consonants. Finalment, dins del grup de les informants valencianes, en Va-MB advertim una distinció intermèdia, de $882 \mathrm{~Hz}$, un valor que indica que la parlant distingeix articulatòriament entre $/ \mathrm{s} / \mathrm{i} / \mathrm{J} /$, però amb el marge típicament reduït descrit per als parlars valencians en la bibliografia (Recasens \& Espinosa 2006, 2007; Recasens 20I4; Cruselles, Herrero \& Jiménez 20I7). 
Taula 4. Agrupacions de les mitjanes de les diferències del valor de centre de gravetat (CDG, en $\mathrm{Hz}$ ) per al contrast /s- S $/$ / vs. / / / (entre parèntesis, desviació estàndard de la diferència). Per a major claredat, ombregem les caselles corresponents a les informants valencianes.

\begin{tabular}{|c|c|c|c|c|c|}
\hline \multirow[b]{2}{*}{ Subjecte } & \multirow[b]{2}{*}{ Casos } & \multicolumn{4}{|c|}{ Agrupacions } \\
\hline & & 1 & 2 & 3 & 4 \\
\hline Va-MC & 7 & $\begin{array}{c}-1.721 \\
(695) \\
\end{array}$ & & & \\
\hline Va-MB & 7 & & $\begin{array}{c}882 \\
(560)\end{array}$ & & \\
\hline VA-SM & 7 & & & $\begin{array}{l}2.563 \\
(399)\end{array}$ & \\
\hline Ro-AC & 7 & & & $\begin{array}{l}3.594 \\
(379)\end{array}$ & $\begin{array}{l}3.594 \\
(379)\end{array}$ \\
\hline Ro-BU & 7 & & & & $\begin{array}{l}3.905 \\
(369)\end{array}$ \\
\hline Ro-CT & 7 & & & & $\begin{array}{l}4.036 \\
(598)\end{array}$ \\
\hline Ro-AM & 7 & & & & $\begin{array}{l}4.448 \\
(1034)\end{array}$ \\
\hline Ro-AD & 7 & & & & $\begin{array}{l}4.776 \\
(383) \\
\end{array}$ \\
\hline Sign. & & 1 & 1 & 0,185 & 0,076 \\
\hline
\end{tabular}

Per contra, en les mitjanes de la diferència del romanés s'adverteix major homogeneïtat, com il.lustra també la Taula 4, amb una possible agrupació de tots els subjectes en un únic conjunt, tot i que amb un grau de probabilitat baix $[p=0,076]$. Aquesta significació reduïda es deu sobretot al fet que la informant Ro-AC presenta una distinció entre /s/ vs. / / menys robusta que la resta de subjectes romaneses analitzades. En aquest sentit, el resultat d'una nova prova ANOVA realitzada sense la informant Ro-AC, en què naturalment se segueixen mantenint diferències significatives $[\mathrm{F}(7,48)=$ I02,566, $p<0,00 \mathrm{I}$ ], provoca que augmente considerablement el grau de probabilitat de l'agrupació en un únic conjunt dels valors de les altres informants romaneses a $p=$ 0,345 (Taula 5). En eliminar de la prova la subjecte Ro-AC, l'efecte produït sobre el grup de la subjecte Va-SM, ara isolada, és major, atés que la probabilitat d'agrupar-la tota sola puja ara a $p=\mathrm{I}$. Totes aquestes variacions, introduïdes per l'exclusió de RoAC, semblen indicar que la subjecte Ro-AC, si bé és un element clarament intermedi, 
realitza una distinció del contrast analitzat que s'aproxima més a la de les informants romaneses, atés que el canvi en la significació de les agrupacions és menor en el grup de les romaneses si s'eliminen els valors d'aquesta informant. El rang dels valors de les mitjanes de les diferències entre les consonants analitzades també mostra la tendència entre les informants valencianes distingidores a una major dispersió en la realització del contrast, tot i excloure la informant no distingidora Va-MC, ja que el rang quedaria en I.68I Hz; per contra, l'interval de realització es redueix fins a I.I8I Hz en el cas de les informants romaneses. En definitiva, l'anàlisi de les dues llengües confirma que el contrast entre les sibilants sordes és més robust i presenta més homogeneïtat en romanés que en valencià. Així, en la Taula 4 es pot comprovar que la informant valenciana amb una realització de l'oposició més clara, amb $2.563 \mathrm{~Hz}$ de diferència entre /s/ i / $/$, no assoleix el grau de distinció del contrast que es dona en romanés: entre $3.594 \mathrm{~Hz}$ i $4.776 \mathrm{~Hz}$.

Taula 5. Agrupacions de les mitjanes de les diferències del valor de centre de gravetat (CDG, en $\mathrm{Hz}$ ) del contrast /s/ vs. / $\mathrm{f} /$ sense la informant Ro-AC, segons el test de Scheffé. Per a major claredat, ombregem les caselles corresponents a les informants valencianes.

\begin{tabular}{|c|c|c|c|c|c|}
\hline Subjecte & Casos & 1 & 2 & 3 & 4 \\
\hline Va-MC & 7 & $\begin{array}{c}-1.721 \\
(695)\end{array}$ & & & \\
\hline Va-MB & 7 & & $\begin{array}{c}882 \\
(560) \\
\end{array}$ & & \\
\hline Va-SM & 7 & & & $\begin{array}{l}2.563 \\
(399) \\
\end{array}$ & \\
\hline Ro-BU & 7 & & & & $\begin{array}{r}3.905 \\
(369) \\
\end{array}$ \\
\hline Ro-CT & 7 & & & & $\begin{array}{l}4.036 \\
(598)\end{array}$ \\
\hline Ro-AM & 7 & & & & $\begin{array}{l}4.448 \\
(1034)\end{array}$ \\
\hline Ro-AD & 7 & & & & $\begin{array}{l}4.776 \\
(383) \\
\end{array}$ \\
\hline Sign. & & 1 & 1 & 1 & 0,345 \\
\hline
\end{tabular}

Gràficament, la realització gradual del contrast estudiat per part de les informants valencianoparlants es percep clarament en el diagrama de dispersió de la Figura I. En aquest gràfic, hi ha creuats els valors de les consonants sibilants sordes analitzades 
per a cadascuna de les informants estudiades. Cada punt representa una consonant alveolar emparellada arbitràriament amb la corresponent consonant palatal, seguint el mètode indicat a la metodologia. A l'eix vertical es representen els valors del CDG de cada sibilant alveolar/s/o /s/: en aquesta dimensió, com més alt siga el valor, més avançada es produeix la consonant (i més diferent de $/ \delta /$ ). I en l'eix horitzontal s'indiquen els valors del CDG de cada sibilant $/ \mathrm{J} /$ : com més reduïts siguen, més posterior és $/ \mathrm{J} /$ (i més diferent de $/ \mathrm{s} /-/ \mathrm{s} /$ ).

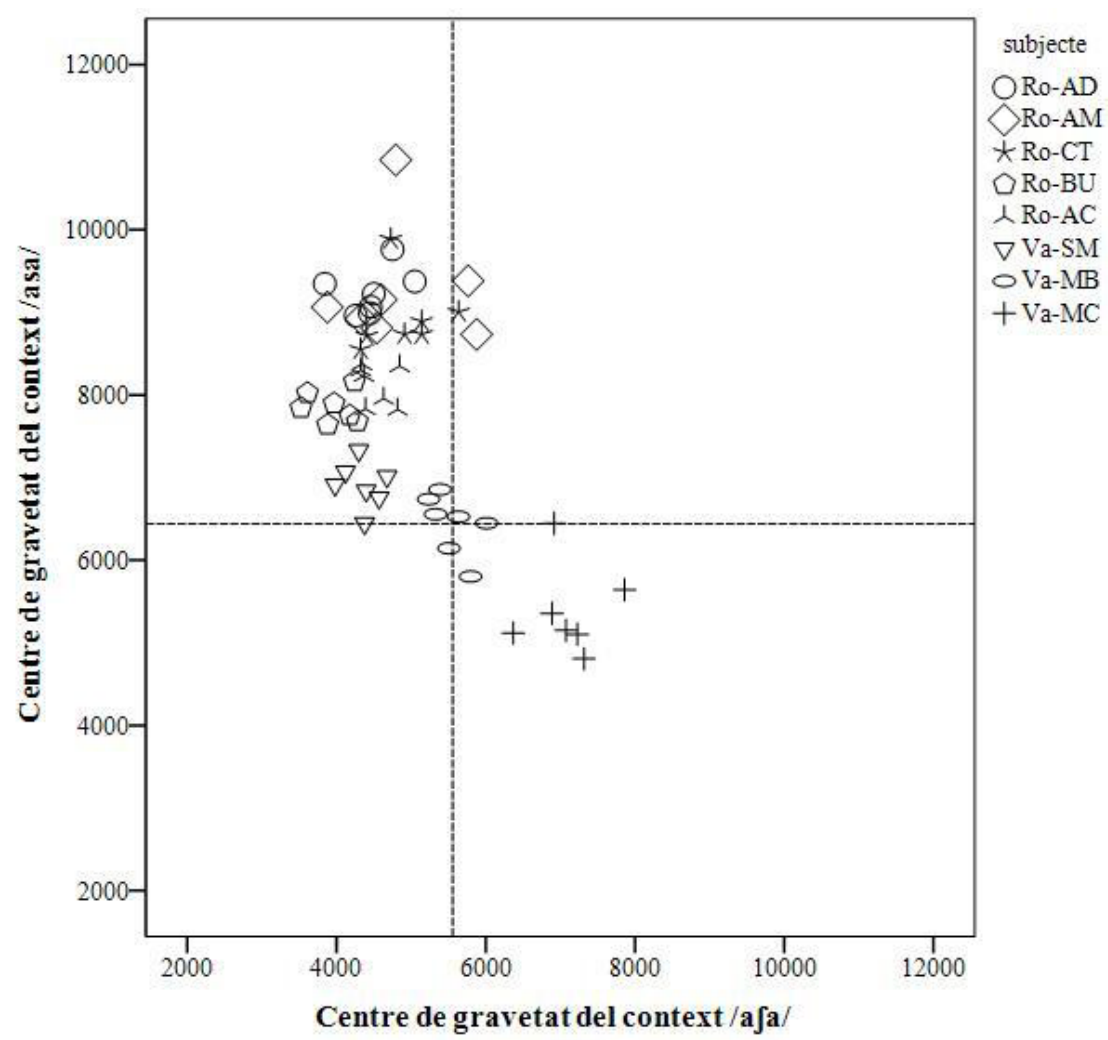

Figura I. Diagrama de dispersió dels valors de cada informant del centre de gravetat (en $\mathrm{Hz}$ ) de les consonants sibilants sordes $/ \mathrm{g} / \mathrm{i} / \mathrm{s} /$ en el context intervocàlic amb la vocal $a$. Les línies discontínues indiquen la mitjana de centre de gravetat de les realitzacions de /s/ (horitzontal) i de / $/$ / (vertical) de la informant amb distinció mínima (Va-MB)

D'aquesta manera, els subjectes amb valors per a $/ \mathrm{g} /$ més baixos (al voltant de 4.000 Hz) i amb valors per a /s/ més alts (superiors a 7.000 Hz), és a dir, els que es troben al quadrant superior esquerre, són els que realitzen una major distinció entre 
Paula Cruselles

Variabilitat en la realització del contrast en les sibilants sordes del català i del romanés

/s/ i /J/. En aquesta posició se situen les informants romaneses; per tant, presenten una distinció extrema entre /s/ i / $/$ /, fet esperable d'acord amb les dades acústiques d'aquestes sibilants. En segon lloc, també en el quadrant esquerre i davall del conjunt de les informants romaneses, troben la informant $\mathrm{Va}-\mathrm{SM}$, la qual diferencia les dues consonants de manera bastant robusta, com es dedueix dels elevats valors de diferència de CDG entre cada parell de /s/ i / $/$, compresos entre $2.070 \mathrm{~Hz}$ i 3.028 $\mathrm{Hz}$. De fet, Va-SM realitza / / en la mateixa freqüència que les informants romaneses, per a qui aquesta consonant sibilant sorda és palatal. No se situa en el nivell de les informants romaneses perquè, com totes les parlants valencianes, presenta valors per al CDG de /s/ per sota de totes les realitzacions d'aquesta sibilant de les informants romaneses. En el centre del diagrama apareix la informant $\mathrm{Va}-\mathrm{MB}$, que distingeix de manera suficient les dues consonants, amb una diferència de CDG entre les consonants emparellades que va de $6 \mathrm{~Hz}$ a $1.505 \mathrm{~Hz}$; aquesta participant presenta una gran variació $\mathrm{i}$ unes distàncies de realització estretes entre les sibilants sordes, prototípiques del valencià. Finalment, en el quadrant inferior dret, se situa la informant Va-MC, amb uns valors majors per a $/ / /$ que per a / $/$ /, fet que apunta cap a la confusió entre les sibilants. En relació amb la variació en la producció de cada tipus de consonant sibilant sorda analitzada, la Figura i mostra clarament que la realització de la / / és bastant homogènia en romanés, amb valors situats aproximadament entre $3.500 \mathrm{~Hz}$ i $5.800 \mathrm{~Hz}$, mentre que la producció de / / / presenta major dispersió, amb realitzacions aproximadament entre $7.600 \mathrm{~Hz}$ i $10.800 \mathrm{~Hz}$. En valencià el grau de variació de /s/ és aproximadament equivalent al romanés, mentre que la consonant $/ \mathrm{g} /$ presenta una major dispersió.

\section{REMARQUES FINALS}

Descriptivament, hem comprovat que la sibilant dental sorda romanesa presenta un valor de mitjana de CDG més elevat que la sibilant alveolar sorda valenciana. Aquest resultat corrobora que la sibilant sorda romanesa es produeix més avançada i en la zona dental, tal com s'indica en la bibliografia (Mallinson 1990: 395; Chițoran 2002: IO); en canvi, la sibilant valenciana equivalent es realitza més endarrerida, a la zona alveolar, fet que provoca un descens en el valor del CDG.

Dins dels grups de les informants valencianes s'ha mostrat que la informant Va-MC, procedent d'Albocàsser (Alt Maestrat), realitza /s/ amb una variació elevada i amb una articulació endarrerida, més palatal que la resta d'informants valencianes analitzades (Va-MB i Va-SM), que procedeixen de Riba-roja del Túria i de Crevi- 
llent, respectivament. Aquesta realització més palatal de /s/ per part de la informant d'Albocàsser podria ser la causant de la neutralització amb $/ \mathrm{J} /$, un fenomen que s'està generalitzant en el dialecte septentrional (Colón 1970) i tortosí del valencià (Gimeno 1994). ${ }^{2}$ Els valors de CDG de /s/ són tan baixos que es produeix fins i tot una inversió de valors amb $/ \mathrm{J} /$. Així, les dades d'aquesta informant semblen mostrar que, una vegada perduda la distinció entre les sibilants /s/ i / $/$, no hi ha un llindar a respectar en la pronúncia de la /s/ per a mantenir la distinció entre les sibilants, de manera que aquest so es pot realitzar més cap enrere. Aquesta mancança de límits es relacionaria també amb la gran variació que es dona en la producció de /s/ per part d'aquesta informant. Les altres dues informants valencianes, Va-MB i Va-SM, realitzen la sibilant /s/ de manera semblant i amb una articulació més avançada, és a dir, més alveolar que l'altra informant valenciana.

La variabilitat en la realització de la /s/ també s'ha advertit entre les informants romaneses, de fet, el rang de freqüències mitjanes de realització de /s/ en romanés és semblant al que es dona entre les informants valencianes, prop de $1.500 \mathrm{~Hz}$ de diferència. En aquest cas, totes provenen del mateix dialecte, per la qual cosa la variació podria apuntar a les característiques fisiològiques de cada informant; no es pot descartar, tanmateix, que siga independent d'aquest factor. ${ }^{3} \mathrm{Com}$ hem vist, la variació es concreta en dues tendències: per una banda, Ro-BU i Ro- $\mathrm{AC}$, amb una realització $\mathrm{de} / \mathrm{s} /$ més posterior, amb freqüències al voltant de $8.000 \mathrm{~Hz}$, i, per una altra banda, Ro-CT, Ro-AD i Ro-AM, amb una realització més anterior, amb freqüències que s'acosten als $9.000 \mathrm{~Hz}$.

Pel que fa a la realització de la $/ \mathrm{J} /$, s'ha constatat que el CDG també és un bon indicador del punt d'articulació. En les informants romaneses s'adverteix una realització endarrerida d'aquesta consonant palatal bastant uniforme (Chițoran 2002: Io), fet que en el nostre estudi es materialitza en un valor de mitjana de CDG baix, aproximadament entre $3.900 \mathrm{~Hz}$ i $4.800 \mathrm{~Hz}$. La realització d'aquesta sibilant sorda en valencià presenta una major heterogeneïtat en la producció; així, tot i les descripcions de / / / en la bibliografia com a sibilant alveolopalatal (Prieto 2004: 200), en el nostre estudi s'ha comprovat que la informant Va-SM, procedent de Crevillent, presenta

2. D'acord amb el suggeriment d'un dels revisors, el model de confusió del contrast /s/ vs. $/ \mathrm{J} /$ podria ser un indici de l'inici d'un procés de despalatalització que s'estén a altres indrets de l'àmbit lingüístic. En aquest estudi, amb tot, atés que es presenta una mostra reduïda d'informants, és complicat comprovar-ho. Les dades completes referides a tot l'àmbit dialectal valencià, efectivament, semblen corroborar aquesta impressió (v. Cruselles 2020).

3. En el cas de les informants valencianes, els trets fisiològics no són clarament l'únic factor que explica la variació, atés que, en un estudi més ampli (Cruselles 2020), s'ha constatat que la distància acústica entre les sibilants sol ser major com més al sud es troba el poble d'on procedeixen les informants. 
Paula Cruselles

Variabilitat en la realització del contrast en les sibilants sordes del català i del romanés

una mitjana de valors de CDG relativament baixos respecte de les altres informants valencianes, al voltant de $4.000 \mathrm{~Hz}$, la qual cosa indica que realitza / $\mathrm{g} /$ també com a palatal, prop de la realització de les informants romaneses. D'altra banda, la informant Va-MC, procedent d'Albocàsser, realitza el so de la grafia $\langle\mathrm{x}\rangle$ en el mot baixar en freqüències elevades, al voltant de $7.000 \mathrm{~Hz}$, un valor típic de les realitzacions alveolars; aquesta producció en freqüències tan elevades, juntament amb el fet que realitza $/ \mathrm{s} /$ en freqüències baixes, demostra que aquesta informant confon totalment les dues sibilants sordes, una dada que s'adiu amb els estudis sobre neutralització del contrast Is/ vs. / J/ en el parlar de Castelló (Colón 1970; Gimeno 1994; Saborit 20I5; Beltran $\&$ Segura-Llopes 20I7). Entre aquestes dues realitzacions de / $/$ /, bé com a palatal bé com a consonant confosa $\mathrm{amb} / \mathrm{s} / \mathrm{i}$, per tant, alveolar, trobem la informant Va-MB, amb una freqüència mitjana de $5.550 \mathrm{~Hz}$, que apunta a una realització alveolopalatal. En conseqüència, es constata una gradació en la realització de la / $/$ / en valencià, que abraça des de la neutralització amb /s/ fins a l'articulació palatal. Aquesta variació en la realització de $/ \int /$ es tradueix en una realització del contrast entre les dues consonants també gradual, amb tres estadis: la manca de distinció (Va-MC), ocasionada per una confusió de les dues sibilants sordes estudiades; una distinció discreta de l'oposició (Va-MB), i una producció altament diferenciada d'aquestes sibilants sordes (Va-SM), semblant a la que es dona en el contrast /s/ vs. / // en romanés. En romanés, en canvi, la distinció del contrast no presenta la distribució en grups del valencià: en aquesta llengua la distinció entre/s/ vs. / / / és clara en totes les informants analitzades (amb una diferència al voltant de $4.000 \mathrm{~Hz}$ ) i el valor de separació entre les sibilants analitzades és major que en valencià. Els resultats indiquen que fins i tot el patró màxim de distinció del valencià és reduït en comparació amb el del romanés, dada que es desconeixia, i que el patró de distinció mínima del valencià és molt divergent respecte del que ocorre en romanés.

En definitiva, l'anàlisi comparativa del contrast entre les fricatives sibilants sordes del valencià i del romanés ens ha permés comprovar que, en valencià, existeix una tendència a tenir tres models de realització del contrast /s/ vs. / / / : per una banda, una manca de distinció acústica, i, per una altra banda, dos tipus de realització del contrast: una distinció acústica mínima i una distinció acústica màxima. La distinció acústica del valencià ha resultat ser molt reduïda, fins i tot en el cas de la distinció màxima, si ho comparem amb la distinció del contrast en romanés. Per tant, sembla evident que, des del punt de vista tipològic, la distinció mínima del valencià és atípica. En una futura investigació, convindria ampliar els informants i aprofundir en l'estudi del contrast entre la sibilant no palatal sorda /s/ i la palatal sorda $/ \mathrm{J} /$, per a confirmar la variació en la realització d'aquest contrast entre aquestes llengües. 
A més, seria interessant una anàlisi perceptiva del contrast estudiat, ja que s'intueix que per als parlants romanesos la distinció màxima del valencià es podria percebre com a reduïda i la mínima esdevenir imperceptible. Aquesta informació, tant acústica com perceptiva, del contrast /s/ vs. / $/$ /, és especialment interessant per a l'ensenyament del català al País Valencià, atés que existeix una gran presència de població romanesa, especialment a la zona septentrional no distingidora. Aquest estudi ens ajudaria a conéixer com perceben i produeixen els nouvinguts les sibilants fricatives sordes del valencià, i ens permetria aprofundir en l'anàlisi de la influència que exerceix l'entorn social sobre la pronúncia, és a dir, ens permetria comprovar si els parlants de segona generació mantenen un contrast entre /s/ i / $/$ robust com els seus pares o imiten la neutralització de la varietat valenciana septentrional.

\author{
Paula Cruselles \\ Universitat de València \\ paula.cruselles@uv.es \\ ORCID 0000-0002-8399-4674
}

\title{
REFERÈNCIES BIBLIOGRÀFIQUES
}

Beltran i Calvo, V. \& C. Segura-Llopes (20I7) Els parlars valencians, València, Universitat de València.

Beltran, V. (1997) El parlar de Benissa, Alacant / Benissa, Institut d'Estudis Joan Gil-Albert / Ajuntament de Benissa.

Boersma, P. \& D. Weenink (2014) Praat: Doing phonetics by computer [Computer program], vers. 5.4.02. [En línia: <http://www.fon.hum.uva.nl/praat>, consulta: I2/02/2019.]

Casanova, E. (I990) «L'evolució dels sistema palatal català: una interpretació», dins V. Martines, J. Martines \& J. J. Ponsoda (eds.), A Sol Post. Estudis de Llengua $i$ Literatura, Alcoi, Marfil, vol. I, p. 45-62.

Chițoran, I. (2002) The phonology of Romanian: a constraint-based approach, Berlín / Nova York, Mouton de Gruyter.

Cicres, J. (2OII) «Los sonidos fricativos sordos y sus implicaciones forenses», Estudios Filológicos, 48, p. 33-48.

Colón, G. (1970) «Sobre el funcionament de les sibilants en el català de Castelló», dins Phonétique et Linguistique Romanes, Mélanges offerts à M. Georges Straka I, Lió / Estrasburg, Société de Linguistique Romane, p. 43-5I. 
Cruselles, P. (2020) «Estudi acústic de les fricatives sibilants sordes del valencià», tesi doctoral, Universitat de València.

Cruselles, P., R. Herrero \& J. Jiménez (20I7) «Propietats acústiques i percepció de contrastos mínims en les sibilants del valencià», Estudios de Fonética Experimental, XXVI, p. 93-I32.

Garcia, J. \& V. Beltran (1994) El parlar de Pedreguer, Pedreguer, Ajuntament de Pedreguer.

Gimeno, L. (1994) Estudi lingüistic dels parlars de les comarques del nord de Castelló, Castelló de la Plana, Societat Castellonenca de Cultura.

Gordon, M., P. Barthmaier, \& K. Sands (2002) «A cross-linguistic acoustic study of voiceless fricatives», Journal of the International Phonetic Association, 32/2, p. I4I-I74. [DOI: https://doi.org/IO.IOI7/Soo25IO030200IO20.]

Hualde, J. I. (20Io) "Neutralización de sibilantes vascas y seseo en castellano», Oihenart. Cuadernos de Lengua y Literatura, 25, p. 89-II6.

IBM Corp. (20I6) IBM SPSS Statistics for Windows, Vers. 24.0, Armonk, IBM Corp. Jiménez, J. (I996) «Problemes de la representació del fonema / $/$ / en català occidental», dins A. Bover i Font, J. Martí Olivella \& M. A. Newman (coords.), Actes del Setè Col-loqui d'Estudis Catalans a Nord-Amèrica, Berkeley, I993, Barcelona, Publicacions de l'Abadia de Montserrat, p. I25-I48.

Jongman, A., R. Wayland \& S. Wong (2000) «Acoustic characteristics of English fricatives», Journal of the Acoustic Society of America, I08/3, p. I252-I263.

LABraña, S. (2005) «Estudio acústico das consoantes fricativas do galego», tesi doctoral, Universitat de València.

Ladefoged, P. \& I. Maddieson (1996) The Sounds of the World's Language, Oxford, Blackwell.

Lamuela, X. (2006) El romanès. Estudi comparatiu entre la gramàtica del català $i$ la del romanès, Barcelona, Generalitat de Catalunya.

Mallinson, G. (I990) "Rumanian», dins M. Harris \& N. Vincent, The Romance Languages, London, Routledge, p. 39I-4I9.

Nebot y PÉrez, J. (1996 [Ia ed. 1984]) Apuntes para una Gramática Valenciana Popular, València, París-València.

Nowak, P. M. (2006) "The role of vowel transitions and frication noise in the perception of Polish sibilants", Journal of Phonetics, 34/2, p. I39-I52. [DOI: https:// doi.org/I0.IOI6/j.wocn.2005.03.00I.]_

Prieto, P. (2004) Fonètica i fonologia: els sons del català, Barcelona, Universitat Oberta de Catalunya. 
Rafel, J. (198I) La lengua fronteriza en el Bajo Aragón meridional: estudio fonológico, Barcelona, Universitat de Barcelona.

Recasens, D. \& A. Espinosa (2006) «Estudi experimental de les consonants fricatives del mallorquí i del valencià», Estudis Romànics, 28, p. I25-150.

- (2007) «An electropalatographic and acoustic study of affricates and fricatives in two Catalan dialects", Journal of the International Phonetic Association, 37/2, p. I43-I72.

Recasens, D. (20I4) Fonètica i fonologia experimental del català: vocals $i$ consonants, Barcelona, Institut d'Estudis Catalans.

Regueira, X. L. \&, M. J. Ginzo (20I9) «A crosslinguistic study of voiceless fricative sibilants in Galician and European Portuguese», dins M. Gibson \& J. Gil (eds.), Romance Phonetics and Phonology, Oxford, Oxford University Press.

Regueira, X. L. (20I4) «Mantenimiento y cambio lingüístico: fricativas sibilantes en gallego", Revista de Filología Románica, 34, p. I5I-168.

Saborit, J. (2009) Millorem la Pronúncia, València, Acadèmia Valenciana de la Llengua.

- (2015) «El valencià de la Plana dins el valencià general», comunicació exposada en la IV Jornada de Taula de Filologia Valenciana (Betxí, 25 d'octubre de 20I5). [En línia: <https://taulafilologiavalenciana.files.wordpress.com/2015/or/ valencia_plana_saborit.pdf>, consulta: I2/02/2019.]

Sanchis Guarner, M. (1950), Gramàtica Valenciana, València, Torre.

SPINU, L. \& J. Lilley (2016) «A comparison of cepstral coefficients and spectral moments in the classification of Romanian fricatives», Journal of Phonetics, 57 , p. 40-58. [DOI: http://dx.doi.org/I0.IOI6/j.wocn.2016.05.002.]

Spinu, L. (2007) «Perceptual Properties of Palatalization in Romanian», dins J. Camacho et alii (eds.), Romance Linguistics 2006. Selected papers from the 36 th Linguistic Symposium on Romance Languages (LSRL), New Brunswick, March-April 2006, Studies in the Theory and History of Linguistic Science IV: Current Issues in Linguistic Theory, 287, Amsterdam, Benjamins, p. 297-310. [DOI: http://dx.doi. org/IO.IO75/cilt.287.22spi.]

- (2010) Palatalization in Romanian: Experimental and Theoretical Approaches. Tesi doctoral, Newark, DE, University of Delaware.

Spinu, L., I. Vogel \& H. Timothy Bunnell (20I2) «Palatalization in Romanian: Acoustic Properties and Perception", Journal of Phonetics, 40/I, p. 54-66.

Univaso, P., M. Martínez Soler \& J. A. Gurlekian (20I4) «Variabilidad intra e inter-hablante de la fricativa sibilante /s/ en el español de Argentina», Estudios de Fonética Experimental, 23, p. 95-I24. 


\section{ANNEX 1}

Taula I. Valors del centre de gravetat (CDG) de $/ \mathrm{s} / \sim / \mathrm{s} / \mathrm{i}$ de $/ \mathrm{J} /$. Els valors de CDG de les sibilants sordes dentals / alveolars $/ \mathrm{s} /-/ \mathrm{s} /$ (quarta columna) i els valors de CDG de les sibilants sordes palatals I $/$ / (sisena columna) s'han extret dels mots que apareixen a les columnes tercera i cinquena, respectivament. En les columnes quarta i sisena els valors s'ordenen, primerament, a partir de la informant que pronuncia la consonant (primera columna), i segonament, a partir de les repeticions de la consonant (segona columna). En la darrera columna s'indica la diferència de CDG entre les consonants sibilant dental / alveolar i la consonant palatal de cada repetició (emparellades arbitràriament a partir del'ordre).

\begin{tabular}{|c|c|c|c|c|c|c|}
\hline Subjecte & Repetició & $\begin{array}{l}\text { Paraula del context } \\
\text { coronal: /asa/ i /asa/ }\end{array}$ & $\begin{array}{l}\mathrm{CDG} \\
/ \mathrm{s} /-/ \mathrm{s} / \\
(\mathrm{en} \mathrm{Hz})\end{array}$ & $\begin{array}{c}\text { Paraula del } \\
\text { context } \\
\text { palatal: } \\
\text { /aja/ }\end{array}$ & $\begin{array}{l}\mathrm{CDG} / \mathrm{s} / \\
(\mathrm{en} \mathrm{Hz})\end{array}$ & $\begin{array}{l}\text { Diferència de } \\
\text { CDG entre } \\
/ \mathrm{s} / / \text { /s/ i / } / \\
(\mathrm{en} \mathrm{Hz})\end{array}$ \\
\hline \multirow{7}{*}{ Ro-AC } & 1 & vasal & 8.234 & aşa & 4.367 & 3.867 \\
\hline & 2 & vasal & 7.959 & aşa & 4.632 & 3.327 \\
\hline & 3 & vasal & 7.825 & aşa & 4.819 & 3.006 \\
\hline & 4 & vasal & 8.350 & aşa & 4.846 & 3.504 \\
\hline & 5 & vasal & 8.375 & aşa & 4.339 & 4.036 \\
\hline & 6 & vasal & 7.832 & aşa & 4.387 & 3.445 \\
\hline & 7 & vasal & 8.302 & aşa & 4.327 & 3.975 \\
\hline \multirow{7}{*}{ Ro-AD } & 1 & vasal & 9.069 & aşa & 4.459 & 4.610 \\
\hline & 2 & vasal & 9.347 & aşa & 3.842 & 5.505 \\
\hline & 3 & vasal & 9.764 & aşa & 4.750 & 5.014 \\
\hline & 4 & vasal & 8.961 & aşa & 4.256 & 4.705 \\
\hline & 5 & vasal & 9.375 & aşa & 5.048 & 4.327 \\
\hline & 6 & vasal & 8.991 & aşa & 4.448 & 4.543 \\
\hline & 7 & vasal & 9.225 & aşa & 4.499 & 4.726 \\
\hline \multirow{7}{*}{ Ro-AM } & 1 & vasal & 9.154 & aşa & 4.598 & 4.556 \\
\hline & 2 & vasal & 9.382 & aşa & 5.765 & 3.617 \\
\hline & 3 & vasal & 9.064 & aşa & 3.876 & 5.188 \\
\hline & 4 & vasal & 10.847 & aşa & 4.794 & 6.053 \\
\hline & 5 & vasal & 8.734 & aşa & 5.878 & 2.856 \\
\hline & 6 & vasal & 8.925 & aşa & 4.329 & 4.596 \\
\hline & 7 & vasal & 8.811 & aşa & 4.539 & 4.272 \\
\hline
\end{tabular}


Paula Cruselles

Variabilitat en la realització del contrast en les sibilants sordes del català $i$ del romanés

\begin{tabular}{|c|c|c|c|c|c|c|}
\hline \multirow{7}{*}{ Ro-BU } & 1 & vasal & 7.900 & aşa & 3.966 & 3.934 \\
\hline & 2 & vasal & 8.025 & aşa & 3.609 & 4.416 \\
\hline & 3 & vasal & 7.844 & aşa & 3.523 & 4.321 \\
\hline & 4 & vasal & 7.641 & aşa & 3.880 & 3.761 \\
\hline & 5 & vasal & 8.164 & aşa & 4.239 & 3.925 \\
\hline & 6 & vasal & 7.679 & aşa & 4.278 & 3.401 \\
\hline & 7 & vasal & 7.752 & aşa & 4.176 & 3.576 \\
\hline \multirow{7}{*}{ Ro-CT } & 1 & vasal & 9.007 & aşa & 5.636 & 3.371 \\
\hline & 2 & vasal & 8.737 & aşa & 5.141 & 3.596 \\
\hline & 3 & vasal & 8.893 & aşa & 5.140 & 3.753 \\
\hline & 4 & vasal & 8.554 & aşa & 4.323 & 4.231 \\
\hline & 5 & vasal & 8.718 & aşa & 4.404 & 4.314 \\
\hline & 6 & vasal & 9.889 & aşa & 4.727 & 5.162 \\
\hline & 7 & vasal & 8.737 & aşa & 4.912 & 3.825 \\
\hline \multirow{7}{*}{ Va-MC } & 1 & passat & 5.103 & baixar & 7.229 & -2.126 \\
\hline & 2 & passat & 5.643 & baixar & 7.862 & -2.219 \\
\hline & 3 & passat & 5.356 & baixar & 6.890 & -1.534 \\
\hline & 4 & passat & 6.446 & baixar & 6.918 & -472 \\
\hline & 5 & passat & 5.118 & baixar & 6.369 & -1.251 \\
\hline & 6 & passat & 5.149 & baixar & 7.077 & -1.928 \\
\hline & 7 & passat & 4.805 & baixar & 7.319 & -2.514 \\
\hline \multirow{7}{*}{ Va-MB } & 1 & passat & 6.856 & baixar & 5.386 & 1.470 \\
\hline & 2 & passat & 6.527 & baixar & 5.634 & 893 \\
\hline & 3 & passat & 6.144 & baixar & 5.507 & 637 \\
\hline & 4 & passat & 6.739 & baixar & 5.234 & 1.505 \\
\hline & 5 & passat & 6.448 & baixar & 6.012 & 436 \\
\hline & 6 & passat & 6.557 & baixar & 5.328 & 1.229 \\
\hline & 7 & passat & 5.802 & baixar & 5.796 & 6 \\
\hline
\end{tabular}


Paula Cruselles

Variabilitat en la realització del contrast en les sibilants sordes del català i del romanés

\begin{tabular}{|c|c|c|c|c|c|c|}
\hline \multirow{7}{*}{ Va-SM } & 1 & passat & 6.841 & baixar & 4.397 & 2.444 \\
\cline { 2 - 7 } & 2 & passat & 6.912 & baixar & 3.980 & 2.932 \\
\cline { 2 - 7 } & 3 & passat & 7.326 & baixar & 4.298 & 3.028 \\
\cline { 2 - 7 } & 4 & passat & 7.012 & baixar & 4.677 & 2.335 \\
\cline { 2 - 7 } & 5 & passat & 6.755 & baixar & 4.571 & 2.184 \\
\cline { 2 - 7 } & 6 & passat & 7.068 & baixar & 4.120 & 2.948 \\
\cline { 2 - 7 } & 7 & passat & 6.446 & baixar & 4.376 & 2.070 \\
\hline
\end{tabular}

